\title{
Laparoscopic hepatectomy versus open hepatectomy for hepatocellular carcinoma: A propensity case-matched analysis of the long-term survival
}

\author{
Kit-Man Ho, Kai-Chi Cheng, Fiona Ka-Man Chan, and Yuk-Pang Yeung \\ Department of Surgery, Kwong Wah Hospital, Hong Kong, China
}

\begin{abstract}
Backgrounds/Aims: Despite the widespread popularity of laparoscopic surgery, laparoscopic liver resection (LLR) remains in evolution. This study aimed to compare the long-term outcomes for patients undergoing laparoscopic versus open hepatectomy for hepatocellular carcinoma $(\mathrm{HCC}) \leq 7 \mathrm{~cm}$. Methods: Patients diagnosed with HCC treated by hepatectomy from October 2000 to May 2019 were included. Excluding tumors larger than $7 \mathrm{~cm}, 1: 2$ propensity score matching was performed between laparoscopic and open hepatectomies. The perioperative outcomes, 5-year overall survival (OS) and disease-free survival (DFS) of the two groups were compared. Results: Forty-five patients who underwent LLR were matched to 90 open hepatectomy $(\mathrm{OH})$ during the same period. LLR group had shorter median hospital stay ( 5 days vs. 9 days, $p=0.00$ ) but required longer operative time $(326.0$ minutes vs. 272.5 minutes, $p=0.018)$ than the $\mathrm{OH}$ group. The 5 -year overall survival was better in the LLR group $(84.9 \%$ vs. $61.1 \% ; p=0.036)$, though there was no significant difference in the 5 -year disease free survival $(20.0 \%$ vs. $22.2 \%, p=0.613)$. The rate of R0 resection was comparable between the 2 groups with a slightly better margin distance in the LLR ( $5 \mathrm{~mm}$ vs. $3 \mathrm{~mm}, p=0.043$ ). Conclusions: Laparoscopic liver resection is safe and feasible for cirrhotic patients with HCC size up to $7 \mathrm{~cm}$. It has better short-term outcomes and comparable perioperative blood loss and complication rates. The resection margin is not jeopardized and the 5-year overall and disease-free survivals are comparable with the open group. (Ann Hepatobiliary Pancreat Surg 2021;25:1-7)
\end{abstract}

Key Words: Hepatocellular carcinoma; Laparoscopic hepatectomy; Survival; Long-term outcome

\section{INTRODUCTION}

The adoption of laparoscopic liver resection as standard practice has been slow. Most centers confined their practice to laparoscopic left lateral sectionectomy and wedge resection. Laparoscopic major resections remained exploratory and were recommended to be carried out in high volume centers only. ${ }^{1-3}$ Concerns hindering its uptake included difficulty in bleeding control, gas embolism, parenchymal transection techniques and oncological safety. ${ }^{1}$ While we are expecting the results from the ORANGE II PLUS trial ${ }^{4}$ on the treatment outcomes, data on the long term outcomes of laparoscopic liver resection (LLR) for malignant liver tumors is still scarce. ${ }^{5-8}$ Technical considerations aside, the adequacy of oncological clearance and long-term survival remains the most important question to be answered. This study aimed to review the long-term outcomes of LLR and open hepatectomy $(\mathrm{OH})$ for a matched cohort of patients with hepatocellular carcinoma and underlying cirrhosis.

\section{MATERIALS AND METHODS}

The clinical data of all patients undergoing hepatectomy for hepatocellular carcinoma (HCC) at our institute from October 2000 to May 2019 were retrospectively analyzed from a prospectively collected database. Patients with typical radiological features of HCC sized $\leq 7 \mathrm{~cm}$ on contrast-computed tomography (CT) or magnetic resonance imaging (MRI) were included. All patients followed the same protocol of perioperative care and investigations. The selection criteria and operating

Received: June 7, 2020; Revised: July 12, 2020; Accepted: July 13, 2020

Corresponding author: Kai-Chi Cheng

Department of Surgery, Kwong Wah Hospital, 25 Waterloo Road, Kowloon, Hong Kong, China Tel: +852-23322311, Fax: +852-35175264, E-mail: thomascheng@hotmail.com

Copyright (C) 2021 by The Korean Association of Hepato-Biliary-Pancreatic Surgery

This is an Open Access article distributed under the terms of the Creative Commons Attribution Non-Commercial License (http://creativecommons.org/ icenses/by-nc/4.0) which permits unrestricted non-commercial use, distribution, and reproduction in any medium, provided the original work is properly cited. Annals of Hepato-Biliary-Pancreatic Surgery - pISSN: 2508-5778 - elSSN: 2508-5859 
technique for LLR and open hepatectomy were described previously. $^{9}$ Drain was placed only when clinically indicated. All operations were performed by the same team of hepatobiliary surgeons.

Liver resection was defined according to the Brisbane 2000 classification. ${ }^{10}$ A gross resection margin of $1 \mathrm{~cm}$ was aimed for all hepatectomies. R0 resection was defined as margin $\geq 1 \mathrm{~mm}$ from the resection surface. Data on post-operative complications was collected from a prospectively managed database and classified according to the Clavien-Dindo Grading. ${ }^{11}$ Post hepatectomy liver failure and bile leakage were defined according to the International Study Group of Liver Surgery (ISGLS) ${ }^{12,13}$. Post-operative mortality was defined as death occurring within 90 days after the operation.

Surveillance liver function tests, alpha fetal protein (AFP) level, triphasic contrast CT scan of the liver were performed at regular intervals. ${ }^{9}$ The date of recurrence was defined as the date of radiological recurrence. Further treatments, such as re-resection, microwave or radiofrequency ablation, trans-arterial chemo-embolization or systemic treatment were given as appropriate.

Propensity score matching was conducted to match patients in the LLR group and $\mathrm{OH}$ group in the ratio ratio of 1:2. Prognostic indicators i.e. age, gender, tumor size, lympho-vascular invasion, alpha-fetoprotein level, R0 resection and presence of cirrhosis were chosen for propensity score calculation. ${ }^{14-21}$ The method of genetic matching was adopted in our study, which automatically optimized the covariate balance between the two groups. ${ }^{22,23}$ The demographic data tumor characteristics, operative data, post-operative outcomes and survival data of the two groups were compared. The analysis was performed according to the intention-to-treat basis.

Statistical analysis was performed with SPSS version 20 (SPSS Inc., Chicago, IL, USA). Mann-Whitney U test was used for continuous variables, and Chi-square test was used for categorical variables. Survival analysis was analyzed by Kaplan-Meier method and compared using the log rank test. Statistical significance was set at $p$-value $\leq 0.05$.

This study was approved by The Hong Kong Hospital Authority, Kowloon West Cluster Research Ethics Committee (reference number KW/EX-17-005 (107-05)).

Table 1. Patients demographics

\begin{tabular}{lccc}
\hline & Laparoscopic $(\mathrm{n}=45)$ & Open $(\mathrm{n}=90)$ & $p$ \\
\hline Age & $62(57.5-68.0)$ & $62(54.75-71.00)$ & 0.737 \\
Gender (male/female) & $37 / 8$ & $72 / 18$ & 0.758 \\
Hepatitis B carrier & $42(93.3 \%)$ & $72(80 \%)$ & 0.125 \\
Hepatitis C carrier & $2(4.4 \%)$ & $11(12.2 \%)$ & 0.000 \\
Child's score & & & 0.055 \\
A & $45(100.0 \%)$ & $83(92.2 \%)$ & \\
B & $0(0.0 \%)$ & $7(7.8 \%)$ & 0.810 \\
Platelet count $\left(\times 10^{9} / \mathrm{L}\right)$ & $146(123.5-201.0)$ & $147.5(106.75-203.0)$ & 0.419 \\
Alpha-fetoprotein $(\mathrm{ng} / \mathrm{ml})$ & $14(4.0-358.5)$ & $21.5(4.75-404.50)$ & \\
\hline
\end{tabular}

Data are shown as median (interquartile range) or number (percentage)

Table 2. Perioperative outcomes and complication rates

\begin{tabular}{lcrc}
\hline & Laparoscopic $(\mathrm{n}=45)$ & Open $(\mathrm{n}=90)$ & $p$ \\
\hline Blood loss (ml) & $500(200-1200)$ & $725(500-1285)$ & 0.055 \\
Transfusion required & $11(24.4 \%)$ & $30(33.3 \%)$ & 0.420 \\
Blood replacement (ml) & $0(0-125)$ & $0(0-600)$ & 0.548 \\
Operative time (min) & $326(256.0-452.5)$ & $272.5(195.00-346.25)$ & 0.018 \\
Pringle maneuvers used & $3(6.7 \%)$ & $26(28.9 \%)$ & 0.003 \\
Hospital stay (days) & $5(4-9)$ & $9(7-16)$ & 0.000 \\
\hline
\end{tabular}

Data are shown as median (interquartile range) or number (percentage) 


\section{RESULTS}

From October 2000 to May 2019, 377 hepatectomies were performed in our institute for hepatocellular carcinoma. Two hundred and forty-nine patients underwent hepatectomies for $\mathrm{HCC} \leq 7 \mathrm{~cm}$ and they were included in the analysis. After matching, there were 45 patients in the LLR group and 90 patients in the $\mathrm{OH}$ group. All patients were Eastern Cooperative Oncology Group (ECOG) performance status 0 . The demographics were depicted in Table 1.

Most of our patients had cirrhosis (84/135, 62.2\%). Less Pringle maneuver was applied in the LLR group (3 vs. $26, p=0.003)$. The intraoperative blood loss was 500 $\mathrm{ml}$ in LLR and $725 \mathrm{ml}$ in $\mathrm{OH}$, though it did not reach statistical significance $(p=0.055)$. The operating time was significantly longer in the LLR group (326.0 minutes vs. 272.5 minutes, $p=0.018$ ). The LLR group had a shorter hospital stay ( 5 days vs. 9 days, $p=0.000$ ) (Table 2). There were less Grade I/II post-operative complications in LLR group and there was no significant difference in the Grade III or above complications (Table 3). There were 5 conversions in the LLR group (11.1\%). The reasons for conversion included dense intra-abdominal adhesions, threatened resection margin, tumor progression with presence of portal vein thrombus and uncertain anatomy.

The tumor characteristics and pathology were depicted in Tables 4, 5 respectively. There was no difference in the multiplicity and size of the tumor between the two groups. The types of resections and the numbers of anatomical resections were also comparable. With a similar
$\mathrm{R} 0$ resection rate, the resection margin was significantly wider in the LLR group (5.0 mm vs. $3.0 \mathrm{~mm}, p=0.043$ ).

The median follow-up period was 36 months in LLR and 43 months in $\mathrm{OH}(p=0.243)$. The median disease-free survival was 29 months and 25 months for LLR and OH; while the median overall survival was 135 months in LLR and 128 months in $\mathrm{OH}$ group respectively. The 1, 3 and 5 -year disease-free survival rates were $80.0 \%, 40.0 \%$, and $20.0 \%$ for LLR; and $73.3 \%, 41.1 \%$, and $22.2 \%$ for $\mathrm{OH}$ ( $p=0.613$ ) (Fig. 1). The 1, 3 and 5-year overall survival

Table 3. Postoperative outcomes

\begin{tabular}{|c|c|c|c|}
\hline & $\begin{array}{l}\text { Laparoscopic } \\
\qquad(\mathrm{n}=45)\end{array}$ & $\begin{array}{l}\text { Open } \\
(\mathrm{n}=90)\end{array}$ & $p$-value \\
\hline Overall complications & $8(17.8 \%)$ & $32(35.6 \%)$ & 0.033 \\
\hline \multicolumn{4}{|l|}{ Clavien-Dindo grade } \\
\hline $\mathrm{I} / \mathrm{II}$ & $7(15.6 \%)$ & $30(33.3 \%)$ & 0.029 \\
\hline $\mathrm{IIIa} / \mathrm{IIIb}$ & $1(2.2 \%)$ & $2(2.2 \%)$ & 1.000 \\
\hline \multicolumn{4}{|l|}{ General complications } \\
\hline Respiratory & 3 & 12 & \\
\hline Urinary tract infection & 0 & 1 & \\
\hline Cardiac & 2 & 1 & \\
\hline \multicolumn{4}{|l|}{ Surgical related } \\
\hline $\begin{array}{l}\text { Wound complications } \\
\text { infection/dehiscence) }\end{array}$ & 2 & 6 & \\
\hline Fluid collection & 1 & 1 & \\
\hline Internal hemorrhage & 0 & 1 & \\
\hline \multicolumn{4}{|l|}{ Liver related } \\
\hline Bile leak & 2 & 0 & \\
\hline $\begin{array}{l}\text { Post hepatectomy } \\
\text { liver failure }\end{array}$ & 1 & 7 & \\
\hline Ascites & 1 & 13 & \\
\hline
\end{tabular}

Data are shown as number (percentage)

Table 4. Type of operations and tumor location

\begin{tabular}{|c|c|c|c|}
\hline & Laparoscopic $(\mathrm{n}=45)$ & Open $(n=90)$ & $p$ \\
\hline Tumor location & & & 0.121 \\
\hline Antero-lateral & $34(75.6 \%)$ & $56(62.2 \%)$ & \\
\hline Postero-superior & $11(24.4 \%)$ & $34(37.8 \%)$ & \\
\hline Anatomical resection & $27(60.0 \%)$ & $61(67.8 \%)$ & 0.371 \\
\hline Non-anatomical resection & $18(40.0 \%)$ & $29(32.2 \%)$ & \\
\hline Type of resection & & & 0.178 \\
\hline Left hepatectomy & $6(13.3 \%)$ & $20(22.2 \%)$ & \\
\hline Right hepatectomy & $4(8.9 \%)$ & $18(20.0 \%)$ & \\
\hline Left lateral sectionectomy & $2(4.4 \%)$ & $6(6.7 \%)$ & \\
\hline Right posterior sectionectomy & $5(11.1 \%)$ & $8(8.9 \%)$ & \\
\hline Right anterior sectionectomy & $0(0.0 \%)$ & $1(1.1 \%)$ & \\
\hline Anatomical monosegmentectomy & $10(22.2 \%)$ & $8(8.9 \%)$ & \\
\hline Wedge resection & $18(40.0 \%)$ & $29(32.2 \%)$ & \\
\hline
\end{tabular}

Data are shown as number (percentage) 
Table 5. Tumor characteristics on histology

\begin{tabular}{|c|c|c|c|}
\hline & Laparoscopic $(\mathrm{n}=45)$ & Open $(n=90)$ & $p$ \\
\hline Tumor size $(\mathrm{cm})$ & $3.5(2-5)$ & $4(3-5)$ & 0.127 \\
\hline Number of tumors & & & 0.117 \\
\hline 1 & $37(82.2 \%)$ & $70(77.8 \%)$ & \\
\hline 2 & $5(11.1 \%)$ & $13(14.4 \%)$ & \\
\hline 3 & $1(2.2 \%)$ & $7(7.8 \%)$ & \\
\hline 4 & $2(4.4 \%)$ & $0(0.0 \%)$ & \\
\hline Cirrhosis in histology & $26(57.8 \%)$ & $58(64.4 \%)$ & 0.451 \\
\hline Lympho-vascular invasion present & $13(28.9 \%)$ & $27(30 \%)$ & 0.894 \\
\hline Satellite lesions present & $4(8.9 \%)$ & $8(8.9 \%)$ & 1.000 \\
\hline Tumor differentiation & & & 0.075 \\
\hline Well & $12(26.7 \%)$ & $19(21.1 \%)$ & \\
\hline Moderate & $18(40.0 \%)$ & $14(15.6 \%)$ & \\
\hline Poor & $3(6.7 \%)$ & $11(12.2 \%)$ & \\
\hline Edmondson-Steiner grade & & & 0.297 \\
\hline I & $2(4.4 \%)$ & $1(1.1 \%)$ & \\
\hline II & $20(44.4 \%)$ & $32(35.6 \%)$ & \\
\hline III & $9(20.0 \%)$ & $18(20.0 \%)$ & \\
\hline IV & $0(0.0 \%)$ & $4(4.4 \%)$ & \\
\hline Resection margin involved & $4(8.9 \%)$ & $8(8.9 \%)$ & 1.000 \\
\hline Resection margin width (mm) & $5(2.25-10.00)$ & $3(0.95-8.00)$ & 0.043 \\
\hline
\end{tabular}

Data are shown as median (interquartile range) or number (percentage)

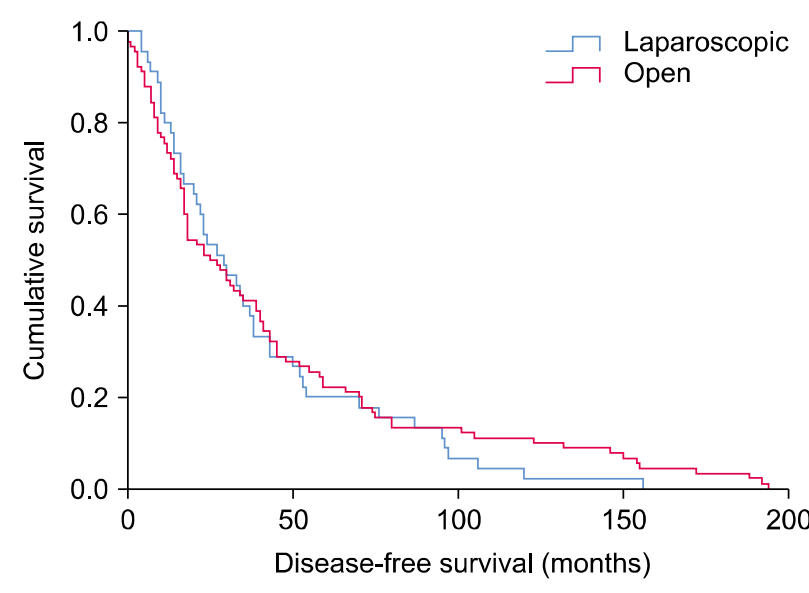

Fig. 1. Kaplan-Meier curve showing disease-free survival of hepatocellular carcinoma patients underwent laparoscopic versus open liver resection.

were $95.6 \%, 84.9 \%$, and $84.9 \%$ in the LLR group, which compared favorably with the $\mathrm{OH}$ group ( $p=0.036$ ) (Fig. 2).

The postoperative outcomes were shown in Table 3 . There were two Clavien Dindo Grade III complications in the laparoscopic group. One patient suffered from duodenal perforation after laparoscopic right posterior sectionectomy, requiring two laparotomies. Another patient developed intra-abdominal collection after left hepatectomy and common bile duct exploration, which was managed

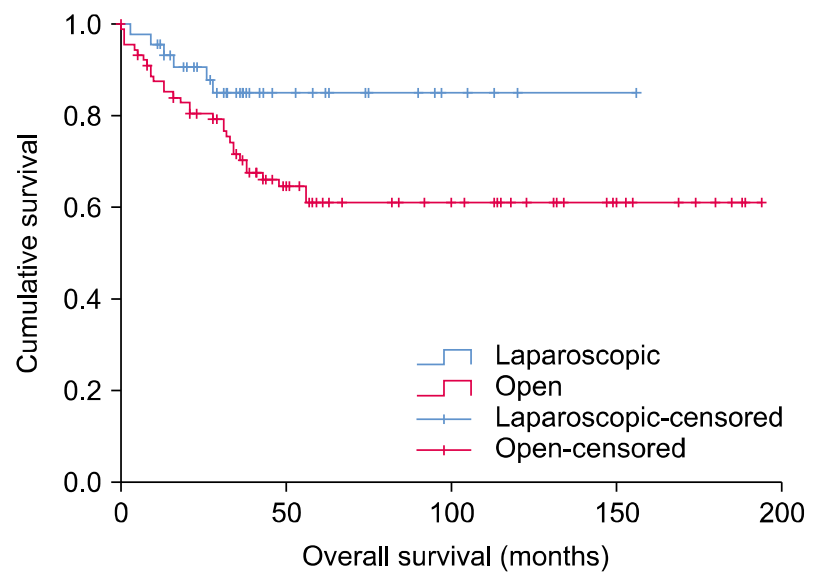

Fig. 2. Kaplan-Meier curve showing overall survival of hepatocellular carcinoma patients underwent laparoscopic versus open liver resection.

by image-guided drainage. There were five post-operative mortalities in the $\mathrm{OH}$ group, all occurred in early stage of our hepatectomy learning curve. Two patients suffered from severe hospital-acquired pneumonia after open right hepatectomy and progressed into multi-organ failure. Three other patients developed progressive liver failure ${ }^{12}$ after right hepatectomy, despite careful patient selection and maximal support. 


\section{DISCUSSION}

Hepatectomy for patients with hepatocellular carcinoma remains a challenge in both the laparoscopic and open era. Most of the patients are hepatitis carrier with underlying liver cirrhosis. The associated portal hypertension, hypersplenism and thrombocytopenia imposes significant bleeding risks during parenchymal transection. ${ }^{10}$ In our series, $62.2 \%$ of the patients had cirrhosis on histology, yet no significant difference was demonstrated in the intraoperative blood loss and transfusion rate between the LLR and open group. With the advances in technology and the improvement in the hemostasis method, laparoscopic liver resection can also be performed safely in cirrhotic patients. Literatures on the short-term outcomes of LLR over the past decades revealed less blood loss, shorter hospital stay and less complications. ${ }^{14-21,24,25}$ Our study showed similar results, though the operating time was longer in the LLR group. The intraoperative blood loss was $500 \mathrm{ml}$ compared with the $725 \mathrm{ml}$ in open group, though the difference did not reach statistical significance. Pringle maneuver was prepared in every patient, but it was not routinely applied during parenchymal transection. Intermittent Pringle maneuver induces ischemic reperfusion injury to the normal liver tissue and their microvasculatures. It was shown to be a significant risk factor for perioperative morbidity and mortality independent of blood loss and transfusion. ${ }^{26}$ The duration of Pringle maneuver was also an independent predictor of poor survival and tumor recurrence. $^{27-29}$ Therefore, Pringle maneuver was applied judiciously in our center, yet the intraoperatively blood loss was not adversely affected in the LLR. The longer operative time in the LLR group could be attributed to the high proportion of patients with cirrhosis in our series, parenchymal transection without Pringle maneuver and hence more difficult hemostasis.

In the Louisville Consensus Statement in $2008,{ }^{1}$ laparoscopic hepatectomy was recommended for tumors smaller than $5 \mathrm{~cm}$. The potential invasion to major vessels, and the anticipated difficulties in achieving inflow or outflow control of the remnant liver might result in increased bleeding risk. Moreover, the large tumor size imposed challenge on retraction and exposure for meticulous dissection. Excessive tumor manipulation was associated with hematogenous dissemination of the tumor cells ${ }^{30,31}$, resulting in potential negative influence on the oncological outcome of LLR. Since then, effort has been made to extend the indications to larger sized tumors. Numerous case reports and case series were published on the technical aspect of LLR. ${ }^{32-38}$ With the magnified view and ability to reach the posterosuperior by flexible high definition video laparoscope, modification of the techniques, development of better dissecting tools and energy source that allows meticulous dissection of vascular and biliary structures ${ }^{37-40}$, the hurdles in exposure and retraction can be overcome. Two single centered studies ${ }^{41,42}$ had shown that LLR was still safe and feasible for tumors sized between 5-10 cm with comparable perioperative outcomes but with shorter hospital stay and less complications. The 1- and 3-year overall and disease-free survival rates of LLR were comparable to open hepatectomy. Therefore, in our center, we extended our selection criteria for LLR to tumor sized up to $7 \mathrm{~cm}$. The short-term outcomes and long-term outcomes were shown to be not adversely affected. Nevertheless, the large tumor size posed additional difficulty in the $\mathrm{LLR}^{43}$ and it should still be cautiously practiced in tertiary centers.

Technical aspects aside, the long-term oncological outcomes and disease-free survival are of utmost importance in determining the role of LLR in management of HCC. Several case matched analyses ${ }^{44-46}$ were published, showing no significant difference in the 5-year overall survival and disease-free survival between LLR and $\mathrm{OH}$, even in patients with cirrhosis. The 5-year overall survival and disease-free survival after LLR for HCC ranged from $50-75 \%$ and $24.0-45.6 \%$ respectively. ${ }^{47-50}$ Our data also showed that the 5-year disease-free survival were comparable between LLR and $\mathrm{OH}$. The patients in the LLR group and $\mathrm{OH}$ group had comparable tumor size, multiplicity and Edmundson-Steniner grading on pathological examination. The resection margin was significantly wider in the LLR group ( $5 \mathrm{~mm}$ vs. $3 \mathrm{~mm}, p=0.043$ ). Similar results were reported in the literature, affirming that laparoscopic liver resection could be performed without compromising the resection margin with careful planning and frequent intraoperative sonographic assessment.

On the other hand, the 5-year overall survival for LLR was better than $\mathrm{OH}(84.9 \%$ vs. $61.1 \%, p=0.036)$ in our series. This could be attributed to the five perioperative mortalities in the $\mathrm{OH}$ group, which occurred all in the first 
half of our hepatectomy experience. ${ }^{9}$ Some of the post-operative complications, such as chest infection and pleural effusions, could be related to the increased trauma and stress induced by open surgical assess.

There were inherent shortcomings in this single-centered retrospective analysis. The relatively small sample size in our series might have underpowered the study results. Moreover, we included patients undergoing hepatectomies from 2000 to 2019. Though all the operations were performed by the same group of dedicated HPB surgeons, the surgical instruments and techniques matured over time. With gaining experience and overcoming the learning curve, the complexity of the operations increased over time. Therefore, propensity score matching was used to minimize the selection bias and effect of potential cofounding covariates. Nonetheless, a properly conducted randomized controlled trial is still warranted in addressing the short term and long-term outcomes of laparoscopic hepatectomy in selected patients. The results of the ongoing ORANGE II PLUS trial ${ }^{4}$ are much anticipated to provide unbiased evidence in this regard.

\section{CONCLUSION}

Laparoscopic liver resection is a safe treatment option for management of hepatocellular carcinoma, even in the presence of cirrhosis and large tumor size up to $7 \mathrm{~cm}$. The intraoperative blood loss and complication rates are not adversely affected, while conferring a benefit of shorter hospital stay. The resection margin is not jeopardized. The oncological outcomes in terms of overall and disease-free survival are comparable with open hepatectomy.

\section{CONFLICT OF INTEREST}

The authors have no conflict of interest to disclose.

\section{ORCID}

Kit-Man Ho: https://orcid.org/0000-0003-3929-4854

Kai-Chi Cheng: https://orcid.org/0000-0002-6440-7825

Fiona Ka-Man Chan: https://orcid.org/0000-0001-9981-0932

Yuk-Pang Yeung: https://orcid.org/0000-0002-2821-871X

\section{AUTHOR CONTRIBUTIONS}

Conceptualization: KCC, YPY. Data Curation: FKMC. Formal analysis, Methodology: KMH, KCC. Writing original draft: $\mathrm{KMH}$. Writing - review and editing: KCC.

\section{REFERENCES}

1. Buell JF, Cherqui D, Geller DA, O'Rourke N, Iannitti D, Dagher I, et al. The international position on laparoscopic liver surgery: the Louisville Statement, 2008. Ann Surg 2009;250:825-830.

2. Wakabayashi G, Cherqui D, Geller DA, Buell JF, Kaneko H, Han HS, et al. Recommendations for laparoscopic liver resection: a report from the Second International Consensus Conference held in Morioka. Ann Surg 2015;261:619-629.

3. Mise Y, Sakamoto Y, Ishizawa T, Kaneko J, Aoki T, Hasegawa $\mathrm{K}$, et al. A worldwide survey of the current daily practice in liver surgery. Liver Cancer 2013;2:55-66.

4. Maastricht University Medical Center. The ORANGE II PLUS trial: open versus laparoscopic hemihepatectomy. Bethesda: U.S. National Library of Medicine; 2020 [cited 2020 Jun 5]. Available from: https://clinicaltrials.gov/ct2/show/NCT01441856.

5. Kazaryan AM, Pavlik Marangos I, Rosseland AR, Røsok BI, Mala T, Villanger O, et al. Laparoscopic liver resection for malignant and benign lesions: ten-year Norwegian single-center experience. Arch Surg 2010;145:34-40.

6. Kaneko H, Takagi S, Otsuka Y, Tsuchiya M, Tamura A, Katagiri $\mathrm{T}$, et al. Laparoscopic liver resection of hepatocellular carcinoma. Am J Surg 2005;189:190-194.

7. Cai XJ, Yang J, Yu H, Liang X, Wang YF, Zhu ZY, et al. Clinical study of laparoscopic versus open hepatectomy for malignant liver tumors. Surg Endosc 2008;22:2350-2356.

8. Belli G, Limongelli P, Fantini C, D’Agostino A, Cioffi L, Belli A, et al. Laparoscopic and open treatment of hepatocellular carcinoma in patients with cirrhosis. Br J Surg 2009;96:1041-1048.

9. Chan FK, Cheng KC, Yeung YP. Laparoscopic liver resection: lessons learnt after 100 cases. Hong Kong Med J 2014;20:386-392.

10. Fan ST. Problems of hepatectomy in cirrhosis. Hepatogastroenterology 1998;45 Suppl 3:1288-1290.

11. Dindo D, Demartines N, Clavien PA. Classification of surgical complications: a new proposal with evaluation in a cohort of 6336 patients and results of a survey. Ann Surg 2004;240:205-213.

12. Rahbari NN, Garden OJ, Padbury R, Brooke-Smith M, Crawford M, Adam R, et al. Posthepatectomy liver failure: a definition and grading by the International Study Group of Liver Surgery (ISGLS). Surgery 2011;149:713-724.

13. Koch M, Garden OJ, Padbury R, Rahbari NN, Adam R, Capussotti L, et al. Bile leakage after hepatobiliary and pancreatic surgery: a definition and grading of severity by the International Study Group of Liver Surgery. Surgery 2011;149:680-688.

14. Simillis C, Constantinides VA, Tekkis PP, Darzi A, Lovegrove $\mathrm{R}$, Jiao $\mathrm{L}$, et al. Laparoscopic versus open hepatic resections for benign and malignant neoplasms--a meta-analysis. Surgery 2007;141:203-211.

15. Croome KP, Yamashita MH. Laparoscopic vs open hepatic resection for benign and malignant tumors: an updated metaanalysis. Arch Surg 2010;145:1109-1118.

16. Lee KF, Cheung YS, Chong CN, Tsang YY, Ng WW, Ling E, et al. Laparoscopic versus open hepatectomy for liver tumours: a case control study. Hong Kong Med J 2007;13:442-448.

17. Han HS, Shehta A, Ahn S, Yoon YS, Cho JY, Choi Y. 
Laparoscopic versus open liver resection for hepatocellular carcinoma: case-matched study with propensity score matching. J Hepatol 2015;63:643-650.

18. Kim H, Suh KS, Lee KW, Yi NJ, Hong G, Suh SW, et al. Long-term outcome of laparoscopic versus open liver resection for hepatocellular carcinoma: a case-controlled study with propensity score matching. Surg Endosc 2014;28:950-960.

19. Tranchart H, Di Giuro G, Lainas P, Roudie J, Agostini H, Franco $D$, et al. Laparoscopic resection for hepatocellular carcinoma: a matched-pair comparative study. Surg Endosc 2010;24:1170-1176.

20. Komatsu S, Brustia R, Goumard C, Perdigao F, Soubrane O, Scatton O. Laparoscopic versus open major hepatectomy for hepatocellular carcinoma: a matched pair analysis. Surg Endosc 2016;30:1965-1974.

21. Cheung TT, Dai WC, Tsang SH, Chan AC, Chok KS, Chan SC, et al. Pure laparoscopic hepatectomy versus open hepatectomy for hepatocellular carcinoma in 110 patients with liver cirrhosis: a propensity analysis at a single center. Ann Surg 2016;264:612-620.

22. Brookhart MA, Schneeweiss S, Rothman KJ, Glynn RJ, Avorn J, Stürmer T. Variable selection for propensity score models. Am J Epidemiol 2006;163:1149-1156.

23. Diamond A, Sekhon JS. Genetic matching for estimating causal effects: a general multivariate matching method for achieving balance in observational studies. Rev Econ Stat 2013;95:932-945.

24. Mirnezami R, Mirnezami AH, Chandrakumaran K, Abu Hilal M, Pearce NW, Primrose JN, et al. Short- and long-term outcomes after laparoscopic and open hepatic resection: systematic review and meta-analysis. HPB (Oxford) 2011;13:295-308.

25. Parks KR, Kuo YH, Davis JM, O' Brien B, Hagopian EJ. Laparoscopic versus open liver resection: a meta-analysis of long-term outcome. HPB (Oxford) 2014;16:109-118.

26. Wei AC, Tung-Ping Poon R, Fan ST, Wong J. Risk factors for perioperative morbidity and mortality after extended hepatectomy for hepatocellular carcinoma. Br J Surg 2003;90:33-41.

27. Man K, Lo CM, Xiao JW, Ng KT, Sun BS, Ng IO, et al. The significance of acute phase small-for-size graft injury on tumor growth and invasiveness after liver transplantation. Ann Surg 2008;247:1049-1057.

28. Liu S, Li X, Li H, Guo L, Zhang B, Gong Z, et al. Longer duration of the Pringle maneuver is associated with hepatocellular carcinoma recurrence following curative resection. J Surg Oncol 2016;114:112-118.

29. Ishizuka M, Kubota K, Kita J, Shimoda M, Kato M, Sawada T. Duration of hepatic vascular inflow clamping and survival after liver resection for hepatocellular carcinoma. $\mathrm{Br} \mathrm{J}$ Surg 2011;98:1284-1290.

30. Liu CL, Fan ST, Lo CM, Tung-Ping Poon R, Wong J. Anterior approach for major right hepatic resection for large hepatocellular carcinoma. Ann Surg 2000;232:25-31.

31. Wong IH, Lau WY, Leung T, Yeo W, Johnson PJ. Hematogenous dissemination of hepatocytes and tumor cells after surgical resection of hepatocellular carcinoma: a quantitative analysis. Clin Cancer Res 1999;5:4021-4027.

32. Ho KM, Han HS, Yoon YS, Cho JY, Choi YR, Jang JS, et al. Laparoscopic anatomical segment 2 segmentectomy by the Glissonian approach. J Laparoendosc Adv Surg Tech A 2017;27: 818-822.

33. Choi H, Han HS, Yoon YS, Cho JY, Choi Y, Jang JY. Laparoscopic anatomic segment 6 liver resection using the Glissonian approach Surg Laparosc Endosc Percutan Tech 2017;27:e22-e25.

34. Lee B, Cho JY, Choi Y, Yoon YS, Han HS. Laparoscopic liver resection in segment 7: hepatic vein first approach with special reference to sufficient resection margin. Surg Oncol 2019;30:87-89.

35. Ho KM, Han HS, Yoon YS, Cho JY, Choi YR, Jang JS, et al. Laparoscopic total caudate lobectomy for hepatocellular carcinoma. J Laparoendosc Adv Surg Tech A 2017;27:1074-1078.

36. Oh D, Kwon CH, Na BG, Lee KW, Cho WT, Lee SH, et al. Surgical techniques for totally laparoscopic caudate lobectomy. J Laparoendosc Adv Surg Tech A 2016;26:689-692.

37. Chiappa A, Bertani E, Biffi R, Zbar AP, Viale G, Pruneri G, et al. Effectiveness of LigaSure diathermy coagulation in liver surgery. Surg Technol Int 2008;17:33-38.

38. Gayet B, Cavaliere D, Vibert E, Perniceni T, Levard H, Denet $\mathrm{C}$, et al. Totally laparoscopic right hepatectomy. Am J Surg 2007;194:685-689.

39. Gumbs AA, Gayet B. Totally laparoscopic left hepatectomy. Surg Endosc 2007;21:1221.

40. Otsuka Y, Kaneko H, Cleary SP, Buell JF, Cai X, Wakabayashi G. What is the best technique in parenchymal transection in laparoscopic liver resection? Comprehensive review for the clinical question on the 2nd International Consensus Conference on Laparoscopic Liver Resection. J Hepatobiliary Pancreat Sci 2015;22:363-370.

41. Ai JH, Li JW, Chen J, Bie P, Wang SG, Zheng SG. Feasibility and safety of laparoscopic liver resection for hepatocellular carcinoma with a tumor size of 5-10 cm. PLoS One 2013;8:e72328.

42. Kwon Y, Han HS, Yoon YS, Cho JY. Are large hepatocellular carcinomas still a contraindication for laparoscopic liver resection? J Laparoendosc Adv Surg Tech A 2015;25:98-102.

43. Ban D, Tanabe M, Ito H, Otsuka Y, Nitta H, Abe Y, et al. A novel difficulty scoring system for laparoscopic liver resection. J Hepatobiliary Pancreat Sci 2014;21:745-753.

44. Sarpel U, Hefti MM, Wisnievsky JP, Roayaie S, Schwartz ME, Labow DM. Outcome for patients treated with laparoscopic versus open resection of hepatocellular carcinoma: case-matched analysis. Ann Surg Oncol 2009;16:1572-1577.

45. Endo Y, Ohta M, Sasaki A, Kai S, Eguchi H, Iwaki K, et al. A comparative study of the long-term outcomes after laparoscopy-assisted and open left lateral hepatectomy for hepatocellular carcinoma. Surg Laparosc Endosc Percutan Tech 2009;19:e171-e174.

46. Aldrighetti L, Guzzetti E, Pulitanò C, Cipriani F, Catena M, Paganelli M, et al. Case-matched analysis of totally laparoscopic versus open liver resection for HCC: short and middle term results. J Surg Oncol 2010;102:82-86.

47. Teramoto K, Kawamura T, Takamatsu S, Noguchi N, Nakamura N, Arii S. Laparoscopic and thoracoscopic partial hepatectomy for hepatocellular carcinoma. World J Surg 2003;27:1131-1136.

48. Chen HY, Juan CC, Ker CG. Laparoscopic liver surgery for patients with hepatocellular carcinoma. Ann Surg Oncol 2008; $15: 800-806$.

49. Lai EC, Tang CN, Yang GP, Li MK. Minimally invasive surgical treatment of hepatocellular carcinoma: long-term outcome. World J Surg 2009;33:2150-2154.

50. Dagher I, Belli G, Fantini C, Laurent A, Tayar C, Lainas P, et al. Laparoscopic hepatectomy for hepatocellular carcinoma: a European experience. J Am Coll Surg 2010;211:16-23. 